Improved communication, understanding of risk perception and ethics related to ionising radiation

This content has been downloaded from IOPscience. Please scroll down to see the full text. 2016 J. Radiol. Prot. 36 E15

(http://iopscience.iop.org/0952-4746/36/2/E15)

View the table of contents for this issue, or go to the journal homepage for more

Download details:

IP Address: 193.190.187.220

This content was downloaded on 06/06/2016 at $15: 32$

Please note that terms and conditions apply. 


\title{
Improved communication, understanding of risk perception and ethics related to ionising radiation
}

\begin{abstract}
In Europe today, institutions, media and the general public exchange information about ionizing radiation and associated risks. However, communication about ionising radiation with the general public has to be further improved, as has been previously highlighted by international responses to the 2011 accident in Japan. This article reports the main activities and findings in this field from the following three FP7 projects: EAGLE, PREPARE and OPERRA and discussed by a broad spectrum of stakeholders at the conference RICOMET 2015. These projects, among other aims, also investigate how communication about ionising radiation in different fields could be improved and harmonised, how radiological risks are perceived, how to encourage ethical considerations in all fields of nuclear applications and what kind of transdisciplinary research is needed. The projects relate to several domains; the first relates to education, training and communication, the second to nuclear emergency preparedness and response, and the third to research and development in the radiation protection field. Incorporation of stakeholder engagement activities such as the RICOMET conference broadens social and ethical aspects and takes them into account during coordination activities as well as during core scientific and nuclear research and development performed in the projects. These activities offered opportunities for moving closer to a citizen-centred ideal of risk communication in particular and nuclear research and development in general.
\end{abstract}

\section{Introduction}

Incorporation of activities to broaden the social and ethical aspects that are taken into account during core scientific and nuclear research and development activities is, in the European society of today, of extreme importance. In order to integrate these activities, a trans-disciplinary approach was applied at different levels in the three FP7 projects: EAGLE (Enhancing Education, Training And Communication Processes For Informed Behaviours And Decision-Making Related To Ionising Radiation Risks), OPERRA (Open Project for the European Radiation Research Area) and PREPARE (Innovative integrated tools and platforms for radiological emergency preparedness and post-accident response in Europe). Among other aims, the RICOMET conference Risk communication, risk perception and ethics about ionising radiation (2015) was organised to present, discuss and 
critically reflect the project results with a broad spectrum of stakeholders: experts in public communication, media representatives, researchers from social sciences, humanities and natural sciences, radiation protection officers, practitioners in nuclear medicine, nuclear power plant operators and other nuclear industry professionals, nuclear safety authorities, various project partners, NGOs and representatives from civil society (http://ricomet2015. sckcen.be).

The conference covered the following topics [1]:

- The role of the media in nuclear and radiological emergencies

- Traditional media in the context of the Fukushima nuclear accident

- Social media in the context of the Fukushima nuclear accident, challenges and opportunities in nuclear emergencies

- Dialogues with journalists reporting about ionising radiation issues

- Quality of information, the role and process of mass media in providing public information in the context of emergency and post-emergency situations as well as in daily life

- Information and participation of the local population and expert-to-expert interactions in nuclear emergency and post-emergency situations in the perspective of the implementation of the Aarhus Convention on access to information, public participation in decision-making and access to justice in environmental matters

- Public understanding of ionising risk information, mental models, challenges and solutions

- Future European research agenda for communication, risk perception and ethics in radiological protection

- The meaning of ethics for radiological protection research and research policy

- Results of on-going or recent research in sociology, psychology, humanities and political science related to:

- Nuclear emergency and post-emergency situations

- Education, training and information

- Communication and stakeholder involvement about new nuclear energy build, nuclear waste management and decommissioning

- Perception of ionising radiation risks

- Radiation protection in medicine

During the conference, activities (including dialogues, round table discussions, focus groups...) clearly showed, among other things, the need for social science research, in particular on risk perception and risk communication, and trans-disciplinary approaches in the field of radiation protection. Discrepancies between the recommendations on communication and public involvement and their practical implementation were recognised. The conference stressed many areas, amongst which was the link and/or communication between hard and soft sciences, where improvements could be made and where additional research and/or coordination would be beneficial. The conference conclusions resulted in the RICOMET conference declaration: Appeal to implement Responsible Research and Innovation in Euratom nuclear research, development and activities [2]. The appeal aims at a deeper integration of social sciences and humanities which resonates with the spirit of the European Research Area (ERA). In line with the Responsible Research and Innovation (RRI) Agenda, the RICOMET conference affirmed that Social Sciences and Humanities can facilitate RRI in a timely and supportive manner. 


\section{Enhancing education, training and communication processes for informed behaviours and decision-making related to ionising radiation risks (EAGLE)}

Education, training and information for the public are key factors in the governance of ionising radiation risks, as are opportunities for dialogue and stakeholder involvement in decision making. The FP7 project EAGLE aims to clarify strategies regarding information and communication in this area. A network of stakeholders-representing sources of information, channels of dissemination and recipients of these-assesses actual practices and needs at a European level. The work aims to identify approaches to support European citizens' better understanding of ionising radiation. EAGLE aims to generate best practice and recommendations, with the ideal of participative, citizen-cantered communication.

Consequently, EAGLE has organised workshops, dialogues and interviews with the public, journalists and information sources, conducted opinion surveys and reviewed mass and social media treatment of ionising radiation topics, including in the aftermath of Fukushima. In addition EAGLE has reviewed existing public opinion data and educational and communication material.

The weight of results points to a big difference between public perception $[3,4]$ and the intentions of those who are providing the information on ionising radiation (IR) risks [4]. On one hand, communication about ionising radiation is still treated too much as a one directional transfer of information from a source to a receiver [5]. Those using IR and those in positions of authority seem mainly inspired by the idea that the general public should be 'educated' by 'explaining the facts'. Materials and practices mostly aim at assisting adults to obtain a better understanding of nuclear technology [6]. In only very few situations are citizens considered as competent stakeholders whose own questions and needs could guide the approach to communication [5].

On the other hand public opinion surveys, investigating the level of basic radiological knowledge in the general public in Belgium, France and Slovenia, found that the knowledge of the general population about ionising radiation is rather limited. The results show that people lack knowledge in basic issues such as, for instance, that exposure to radiation does not necessarily lead to contamination, (64\% of representative population answered incorrectly to this question in Belgium [7], 88\% in France [8] and 81\% in Slovenia [9]).

In some European countries, basic elements on IR are provided in schools, from the age of (10-14) years and pursued by students of (14-18) years; the subject is not mandatory and the teacher may choose whether to teach it or not, although the Fukushima accident increased attention to this topic. In other countries IR is explained to a very limited extent at pre-university levels [3]. It would be worth developing the subject and harmonising the shared knowledge in European schools.

Journalists, as a bridge between the general public and experts or authorities [10] are very reluctant to work with public-relations professionals who in many EU institutions are responsible for communication. They appeal for the IR experts to be trained for media communication, and to be able to provide information even under uncertainty [11]. During a nuclear emergency, the traditional media were found to provide a broad context including frequent comparisons with previous accidents, however the experts' technical vocabulary of radiation appeared to be inadequately translated [12] for public understanding. In the case of the Fukushima accident, institutions used social media mainly as an expedient when traditional websites crashed under the weight of consultation. In contrast, a form of 'citizen journalism' emerged where social networks sped, decentralised and diversified information provision while offering platforms for direct citizen participation, expression and feedback [12].

As a result of its activities, EAGLE identified areas for improvement in communication about ionising radiation. Among others, these areas include the following: 
- Public opinion research is mainly focused on EU citizens' attitudes towards nuclear energy, and omits other IR applications or challenges. EAGLE suggests identifying the actual impacts of IR risks in everyday life and focussing on issues meaningful to the public.

- Societal communication about IR risks has become more complex, extensive and multidirectional. EAGLE suggests more joint learning and participative problem-solving. The final aim, shared by professionals in institutions and by scientific journalists, is to help develop a risk culture: the awareness that dangers and consequences exist, but also protective actions that can be taken by authorities or by citizens themselves.

- The new media speeds up, decentralises and diversifies information provision while offering platforms for direct citizen participation, expression and feedback. EAGLE identified the need for institutions to adapt with new personnel, new practices and new policies related to communication and public involvement.

- The ideal of communication about radiological risks is to support stakeholders to make informed decisions and to establish two-way communication with joint problem solving. In order to take an informed decision, people need a certain level of understanding of the issue. Research shows that communication related to the field of radiological protection will not trigger enough attention to be heard or recalled among people with low levels of knowledge; consequently they will not be able to engage in the decision-making process. From this point of view, teachers in schools and other people involved in education programmes have an important role in risk communication and public understanding.

The EAGLE activities promote (a) increasing reflexivity and transparency of education, training and education in the nuclear domain; (b) better European dissemination of tested and appropriate methods and materials developed at national level; (c) better integration of diverse stakeholders' characteristics and needs; (d) a contribution towards better accident preparedness for nuclear host communities but also for nuclearized member states overall.

In today's democratic context, and with specific reference to the transparency requirements that areincreasingly important in the nuclear domain, even small increments in the described directions are desirable. Overall, the EAGLE coordination activities can make a contribution, real if not radical, to the systems of nuclear safety and public health security.

\section{Innovative integrated tools and platforms for radiological emergency preparedness and post-accident response in Europe (PREPARE)}

In order to close gaps that have been identified in nuclear and radiological preparedness in Europe following the first evaluation of the Fukushima accident, the project PREPARE addressed the review of existing emergency preparedness and response (EPR) procedures for dealing with long-lasting releases, cross-border problems in monitoring and food safety. In addition it developed missing functionalities in decision support systems ranging from improved source term estimation and dispersion modeling to the inclusion of hydrological pathways for European water bodies including societal aspects. As the management of the Fukushima event in Europe was not optimal, a so called Analytical Platform has been developed to explore the scientific, operational and societal means to improve information collection, information exchange and the evaluation of such types of disasters. This has been achieved through a collaboration of industry, research and governmental organisations in Europe taking into account the networking activities carried out under the NERIS-TP project (Towards a self-sustaining European Technology Platform on Preparedness for Nuclear and Radiological Emergency Response and Recovery). 
The activities of the PREPARE project have addressed preparedness and response from a technical and societal point of view as well as, among other things, preparing an extensive tasks dealing with trustworthiness of information. The Analytical Platform (AP) for information exchange during a nuclear or radiological crisis allows discussion between institutional and non-institutional experts on an expert level and widespread congruent information on the current situation to the public particularly using mass media. To support the experts in the IR analysis, a knowledge database has been developed that contains historic events and scenarios, their propagation with time, and applied countermeasures. Using the methodology, case-based reasoning (CBR) solutions can be found for events that are not part of the database. Historic cases from Chernobyl and scenarios prepared with the RODOS system (Real-time On-line DecisiOn Support), approved by experts, populate the data base. The usage of this tool will be further explored with interested organisations in Europe.

Stakeholder panels have been set-up in Belgium, Finland, France, Switzerland, Greece, Ireland, the Netherlands, Norway, Portugal, Spain and the United Kingdom to review existing guidance related to the management of contaminated goods and communication about goods in order to identify areas for improvement. The results will help in designing and strengthening preparedness plans for post-accidental situations at national and local levels in European countries, including addressing communication to match stakeholders' needs and expectations.

Communication with the public in a case of a nuclear emergency was extensively addressed in the project. The overall objective was to investigate the conditions and means for relevant, reliable and trustworthy information to be made available to the public at the appropriate time and according to its needs, both during the nuclear emergency as well as in the postemergency phases. Both traditional and social media have been studied.

As a conclusion one can state that PREPARE improved the tools and methods on topics such as long-lasting releases, source-term estimation, model improvements, knowledge gathering and exchange of trustworthy information. The project was clearly driven from the observations during and after the Fukushima accident. PREPARE is a step forward in the harmonisation of emergency management and rehabilitation preparedness in Europe, as it provides tools and methodologies that can be used by national organisations and implemented in decisions support systems such as ARGOS and RODOS but also involves non-governmental stakeholders to gather and disseminate trustworthy information. In particular in the latter area, PREPARE and EAGLE interacted and identified synergies. This clearly demonstrates that social and ethical aspects are an integral part of emergency management preparedness and long-term recovery.

\section{Open project for European radiation research area (OPERRA)}

The OPERRA project aims to build up a coordination structure that has the legal and logistical capacity to administer future calls for research proposals in radiation protection on behalf of the European Commission. Among OPERRA's initiatives are the set-up of a sustainable mechanism to manage radiation protection research in Europe; the involvement of key partners in radiation protection as well as national and international funding agencies; and the enrolment of universities and academic partners, notably from new EU Member States, major stakeholders and authorities as well as other technical platforms inside and outside Euratom.

Joint programming of radiation protection research and education \& training, though respecting the specificities of each particular domain (low-dose risk research, radioecology, emergency preparedness and response, dosimetry, medical applications of ionising radiation) and related strategic research agendas, helps in the clarification of priorities for research over the entire scope of radiation protection, taking into account stakeholders, societal needs, and decision-makers on the one hand, and researchers on the other hand. So the OPERRA consortium 
aims to bring together many of the major European players in radiation protection research and related research platforms to maximise coordination of research efforts, identify research methodologies and techniques/approaches that have not been applied effectively and to provide strategic direction and leadership in this area of importance in energy production, medicine and a range of other uses beneficial to the European population. Radiation workers, patients and the public are rightly concerned that their health and the environment are not compromised unduly by the various uses (or indeed misuses) of ionising radiation and radioactive materials. OPERRA aims to address these concerns by promoting research that will ensure that health risks are better understood and quantified, and that identifies improved approaches to radiation protection in relation to occupational, medical, environmental and accidental exposures.

OPERRA has already dedicated special attention to two activities reaching out to stakeholders, universities and professional partners. In preparation for the organisation of a first workshop on ethics, risk communication and risk perception, institutions involved in risk communication, risk perception and the ethics of radiation protection in Europe have been identified by using five different databases. Although the OPERRA partners managed to identify many institutions dealing with the topics in almost every EU country, the overall list of institutions shows that only a few research groups in the EU established in the field and professionally competent to conduct research into risk communication, risk perception and the ethics of radiation protection. These few identified groups are trans-disciplinary and collaborate with research institutes and academia (as co-authors on scientific articles, book chapters and attendees of conferences in social science, humanities and natural science). The entire list of institutions gave a good starting point for the European Commission in order to enhance a trans-disciplinary approach to risk communication, risk perception, and the ethics of radiation protection.

In most cases, communication and risk perception research in the nuclear field has been approached either by social scientists or by nuclear experts. For the most part, academic institutions mainly address risk communication and risk perception in general, with the ionising radiation field being taken only once or twice as a case-study, thus without taking into account any of its specificity. In other words, universities investigate communication and risk perception related to ionising radiation more in terms of a scientific adventure, rather than as a prerequisite for building an intellectual and theoretical capacity for both scientists and the public at large. On the other hand, nuclear institutions exploring communication and risk perception do not tend to apply a trans-disciplinary approach which results in a rather weak and inconsistent recognition in the field. Thus, it is recognized that research in this field should be inherently interdisciplinary, as it embodies several research domains: risk communication, risk perception, radiation protection, emergency management, opinion formation, ethics and finally, behaviour.

The second major activity consisted of developing a stakeholder management strategy and a stakeholder questionnaire on research priorities in radiation protection. This questionnaire was developed to stimulate an active dialogue with all parties and to gather stakeholder views on (i) the key issues in radiation protection that would benefit from an improved evidence base and from an enlarged societal debate including reflections on ethics, (ii) the most promising approaches to addressing the key issues, and (iii) the timeframe and resource requirements for proposed research activities.

The answers to the questionnaire clearly showed that ethical aspects related to the use of nuclear technology, and risk communication and perception should be included in future research priorities. A majority of the respondents stated that a separate Strategic Research Agenda (SRA) related to social sciences and humanities would be useful. Finally, uncertainties related to lowdose effects were recognized as one of the main challenges to efficient risk communication.

The OPERRA project is one of the first EC-funded project bringing together a wide range of scientists from the communities worried about radiation protection research and has clearly 
demonstrated already that radiation protection stakeholders can no longer ignore the relevance and added value of implementing research addressing risk perception, risk communication and ethics, in close connection with 'hard science' researchers.

\section{Conclusions}

The EAGLE, OPERRA and PREPARE project results as well as those of the RICOMET conference highlighted that areas such as medical, industrial and nuclear energy applications of ionising radiation research and development, as well as emergency management and rehabilitation, can undoubtedly benefit from the social sciences and humanities. This includes, among other aspects, enabling stakeholders to be involved in nuclear research policy. Shaping research and development pathways in socially desirable ways implies trans-disciplinary methodological approaches and activities to build strong societal justification.

The public declaration [2], published after the RICOMET conference, appeals for implementation of responsible innovation in nuclear research and development with activities to promote the further integration of social sciences and humanities. The appeal resonates with the spirit of the European Research Area (ERA). In the working document Science, society and the citizen in Europe, emphasizing the 'growing scepticism' and 'hostility' of society towards advances in knowledge and technology, the European Commission argues that the relationships between science, technology and society "have to change because of the impact of science and research on competitiveness, growth and jobs and on the quality of life in Europe'. In the more specific context of the Framework Programmes, the European Commission states that 'for Europe to become the most advanced knowledge society in the world, it is imperative that legitimate societal concerns and needs concerning science and technology development are taken on board' (Work Programme 2007, Capacities, Part 5, Science in Society).

Addressing the social, ethical and participatory dimensions of nuclear research and development offers great opportunities for the development of trans-disciplinary projects in the nuclear field and collaborations with partners from multiple disciplines that embrace a range of issues, dimensions and expertise. Such research and development, including what is commonly called 'governance' aspects, allows researchers from related fields of nuclear technology, radiological protection, safety and emergency response to assume their responsibility towards European societyby responding to the expectations of both the authorities and the public [2].

\section{References}

[1] Perko T et al 2015 Book of Abstracts Int. Conf. on Risk Perception, Communication and Ethics of Exposures to Ionising Radiation (RICOMET) (Mol, Belgium, 2015) p 100

[2] Perko T, Jourdain J R and Raskob W 2015 Public Declaration after the RICOMET Conf:: Appeal to Implement Responsible Research and Innovation in Euratom Nuclear Research, Development and Activities (http://ricomet2015.sckcen.be/ /media/Files/Ricomet2015/RICOMETdeclaration. pdf?la=en)

[3] Turcanu C et al 2014 Report on public views across EU on education and information in the postFukushima context FP7 EAGLE, D3.1 ed T Perko (Brussels: European Commission) p 248

[4] Železnik N et al 2015 Lay public mental models of ionizing radiation: representations and risk perception in four European countries FP7 Project EAGLE ed T Perko (Brussels: European Commission)

[5] Železnik N, Marega M and Koron B 2014 Report from initial project conference: let's communicate about ionising radiation EAGLE, D4.1 ed T Perko (Brussels: European Commission) p 82

[6] Istenic R and Kralj M 2014 Analyses of ETI material in EU related to Fukushima accident EAGLE, D1.2 ed T Perko (Brussels: European Commission) p 26 
[7] Turcanu C and Perko T 2014 The SCK $\bullet$ CEN barometer 2013: perceptions and attitudes towards nuclear technologies in the Belgian population SCK•CEN-BLG-1097 (Mol: SCK•CEN) p 111

[8] El Jammal E M and Rollinger F 2014 Public information and knowledge in the nuclear field DSDP Report No. 143 (Paris: IRSN) p 39

[9] Kralj M, Daris I and Istenic R 2014 Report on public views on education and information in the post-Fukushima context in Slovenia ed T Perko (Brussels: European Commission)

[10] Perko T 2014 Radiation risk perception: a discrepancy between the experts and the general population J. Environ. Radioact. 133 86-91

[11] Valuch $\mathrm{J}$ et al 2015 Materials for international dialogue: output of national-level dialogues for discussion EAGLE, D2.4 ed T Perko (Brussels: European Commission) p 21

[12] Perko T et al 2015 Mass and new media: review of framing, treatment and sources in reporting on Fukushima J. Mass Commun. Journalism 5252

\section{Tanja Perko}

$\mathrm{SCK} \bullet \mathrm{CEN}$, University Antwerpen, EAGLE coordinator, Belgium

E-mail: tperko@sckcen.be

\section{Wolfgang Raskob}

KIT, PREPARE coordinator, Germany

E-mail: wolfgang.raskob@kit.edu

\section{Jean-Rene Jourdain}

IRSN, OPERRA coordinator, France

E-mail: Jean-Rene.Jourdain@irsn.fr 